\title{
Anti-diabetic role of quercetin and cinnamon on neurobehavioral alterations and biochemical parameters of induced diabetics rats
}

\author{
Fella Boudiaf (D). Ibtissem Chouba • Naziha Amri • Abdelkarim Tahraoui
}

\author{
F Boudiaf (Corresponding author) - I Chouba - N Amri • A email: floulouboudiaf@gmail.com \\ Tahraoui \\ Applied Neuroendocrinology Laboratory, Université Badji \\ Mokhtar - sidi amar - biologie, Annaba, Algeria.
}

Received: May 01, 2020 • Accepted: May 21, 2020 • Published Online: May 29, 2020

\begin{abstract}
We aim was to evaluate the protective effects of the antioxidants cinnamon and quercetin on neurobehavioral alterations and complications, besides biochemical parameters of induced-diabetics Wistar rats. Diabetes was induced by a single intraperitoneal injection of streptozotocin at a dose of (45 $\mathrm{mg} / \mathrm{kg}$ ). The administration of streptozotocin was considered acting on anxiety behaviors and biochemical parameters in adult Wistar rats. On the other hand, the protective role of antioxidants (cinnamon and quercetin) on streptozotocin-induced disorders was also evaluated. Behavioral tests in the open field (OF) revealed that diabetic animals exhibited an anxious behavior and an alteration in the locomotive and exploratory activities when compared to control. The administration of the cinnamon $(2 \mathrm{~g} / \mathrm{kg})$ and Quercetin $(0.5 \mathrm{~g} / \mathrm{kg})$ by gastric gavage reduces anxiety and decreases hyperglycemia-related harm. However, antioxidants cinnamon and quercetin administration significantly alleviated anxious and depressive behaviors.
\end{abstract}

Keywords: antioxidants, anxiety, diabetes

\section{Introduction}

Diabetes is a significant health problem whose frequency is increasing. It results in severe acute complications (hypoglycemia, hyperglycemia) or chronic ones (ophthalmic problems, nephropathy, neuropathy, and foot problems (Wens et al 2007). This pathology has been known for many years, and given its growing prevalence around the world, scientists have been working on different treatments attempting to reduce it (Deplech 2015).

To understand the pathophysiological mechanisms associated with the diabetic syndrome, it is possible to reproduce in animals a diabetic state simulating human diabetes by various experimental methods: chemical, surgical, or genetic (immunological) (Etuk and Muhammed 2010).
Streptozotocin, in high doses, destroys B cells; at low and repeated dose, it induces insulitis followed by the destruction of $\mathrm{B}$ cells by a $\mathrm{T}$ cell-dependent immune mechanism (Grimaldi 2000). The peripheral neurological complications of diabetes are frequent, various, inaugural, or latent (Ghika et al 2003).

Stress has long been considered as an important factor in type 2 diabetes. However, it is only recently that researches have shown how stress can play a role in triggering diabetes and controlling blood sugar for people with diabetes (Surwit 2002).

Research is showing more and more the relationship between mental disorders and diabetes. People with serious mental disorders, particularly those with depressive symptoms or syndromes, and people with diabetes have reciprocal susceptibility and a high rate of conditions involving mental health (David et al 2013).

Nowadays, the therapeutic virtues of plants are showing renewed interest thanks to the improvement of extractive techniques and the progress of structural analysis methods for the discovery of new active principles (Saffidine 2015).

The polyphenols form an important group of natural substances that are widespread in the plant world (Urquiaga 2000; Saffidine 2015). Flavonoids are the main group of polyphenols, with more than 9000 different compounds and distributed in a general way (Hernández 2009; Saffidine 2015). They are amongst the most representative substances produced by plants through their secondary metabolism; these substances possess coloring, aromatic, medicinal, and cosmetological properties and confer on the plant's adaptive advantages. Many active ingredients are beneficial to humans and animals (Saffidine 2015); they are recognized primarily for their antioxidant action (Bruneton 1999).

In this context, we aim was to evaluate the protective effects of the antioxidants Cinnamon and Quercetin on 
neurobehavioral alterations and complications, besides biochemical parameters of induced- diabetics Wistar rats.

\section{Materials and Methods}

\section{Biological material}

The basic biological material we have opted for is the white rat of the Wistar strain from the Pasteur Institute in Algiers. On arrival, these rats weighed on average 150 grams, and at the time of the experiment, they weighed on average $210 \pm 20$ grams. These animals were acclimated to the conditions of the animal house, at a temperature of $25 \pm 2{ }^{\circ} \mathrm{C}$, a hygrometry of $50 \%$, and a natural photoperiod (spring). The food provided to the animals is made in the form of sticks consisting of corn, barley, milk, and vitamin supplements (GAE: Eastern Agricultural Group, Bejaia). As for drinking water, it is presented in bottles adapted to the cages. Food and water are provided ad libitum.

After a three-week adaptation period, we selected twenty-four weight-based rats (approximately 220 grams) which were separated into 4 experimentais batches: control group (T) $[\mathrm{n}=6]$, diabetic lot treated with quercetin (DQ) [n $=6]$, quercetin and cinnamon treated diabetic lot (DQC) $[\mathrm{n}=$ 6], a non-diabetic lot treated with quercetin $(\mathrm{Q})[\mathrm{n}=6]$ and a non-diabetic lot treated with quercetin and cinnamon (QC) [n $=6]$. This study followed the guidelines of ethics on the animals used in experiments.

\section{Administration of Streptozotocin}

The induction of diabetes in the DQ and DQC lots was achieved by a single intraperitoneal injection (IP Inj) of STZ (Sigma ST Lowis, Mo) at a dose of $45 \mathrm{mg} / \mathrm{kg}$ of body weight, i.e., a volume of $1 \mathrm{ml} / \mathrm{kg}$. Streptozotocin was prepared extemporaneously in $0.1 \mathrm{M}$ citrate buffer ( $\mathrm{pH} 4.5$ ). Lots $\mathrm{Q}$ and QC received only one IP Inj of the citrate buffer.

\section{Administration of quercetin and cinnamon}

Quercetin used for the treatment of rats is a yellow powder. The preparation of the corresponding dose depends on the weight of the rats at $5 \mathrm{mg} / \mathrm{kg}$. Cinnamon is in the form of ocher powder. To prepare the correct dose, a precision scale was used to measure the weight of the rat $2 g$ of cinnamon per
$1 \mathrm{~kg}$ of body weight. Quantified doses are added to Eppendorf tubes to be dissolved with $1 \mathrm{ml}, 0.9 \%$ saline per $\mathrm{kg}$ body weight. The start of treatment with quercetin and cinnamon begins on the $7^{\text {th }}$ day after the induction of diabetes and is administered by gastric gavage of rats for 7 days (duration of treatment). The treatment with cinnamon is used for lot D, Q, $\mathrm{C}$, and $\mathrm{Q}, \mathrm{C}$ every other day of the total administration period of 7 days.

The quercetin that we used is the Quercetin $\geq 95 \%$ (HPLC), solid 2- (3,4dihydroxyphenyl). The cinnamon we used is Natrol Cinnamon Extract $1000 \mathrm{mg} 80$ tablets, which is composed of cinnamon bark extract, calcium phosphate dibasic, stabilizer (cellulose), anti-caking agents (stearic acid, silicon dioxide, carboxymethylcellulose, magnesium stearate, methylcellulose, glycerin.

\section{Open-field test (OF)}

The Open Field test, originally described by Hall in 1934, was developed to measure differences in emotional reactivity in rats. The open-field test is performed for 5 minutes and the animal is placed in the center of a device (Sáenzet et al., 2006). Its displacement allows measuring the number of squares traversed as well as the time spent in each zone. Consequently, this test indicates locomotor activity and anxious behavior respectively. The latter is more noticed when the rat spends more time in the peripheral zone. As for the central zone, its exploration represents a sign of less anxiety.

\section{Determination of the glycemic profile}

During the experiment, the determination of the glycemic profile was preceded in two evolutionary and precise periods in all the rats included in the study. For this step, a manual glucometer (ONE TOUCH ultra ${ }^{\circledR}$ ) was available to instantly measure blood glucose (expressed in $\mathrm{g} / \mathrm{l}$ ) from the caudal vein (Hiramatsu et al 2002) of each rat at day 4 and 14.

\section{Measurement of triglycerides}

Enzyme techniques are used by most laboratories. They are based on the enzymatic dosage of glycerol released after the action of lipase. The most used technique is that using the oxidase - peroxidase couple:

$$
\text { Triglycerides lipase } \longrightarrow \text { Glycerol }+03 \text { Fatty acids }
$$

\footnotetext{
Glycerol + ATP Glycerol Kinase Glycerol 3 phosphate + ADP

Glycerol 3 phosphate Glycerol oxidase $\rightarrow$ Dihydroxyacetone phosphate $+\mathrm{H} 2 \mathrm{O} 2$

$2 \mathrm{H} 2 \mathrm{O} 2+$ Phenol + amino 4 phenazone Peroxidase Quinone colored imine $+4 \mathrm{H} 2 \mathrm{O}$
} 
The colorimetric reading was made at $540 \mathrm{~nm}$ and normal levels were considered when $<1.50 \mathrm{~g} / \mathrm{l}$. To establish a diet and/or treatment, the pathological threshold was equal to or greater than $2 \mathrm{~g} / \mathrm{l}$.

\section{Statistical treatment of the data}

The results were represented as mean and standard error (Mean \pm SEM). The comparison between the different groups was performed by student t-test analysis. The statistical analysis of the data was performed using the PRISM software (Version 6.0).

\section{Results}

\section{Blood glucose Level}

During this experiment, blood glucose (g/l) was measured on day 4 and day 15. Streptozotocin caused highly significant hyperglycemia $(P<0.001)$ from the $4^{\text {th }}$ day of the experiment in the diabetic quercetin (DQ) batch as well as the quercetin cinnamic diabetic (QCD) batch compared to the control group (T). After administration of the antioxidants, the two diabetic lots (DQ) and (DCQ) reveal a very significant decrease $(P<0.01)$ of the blood glucose level in day 15 compared to that of day 4.

\section{Variation of the open field test parameters}

The results obtained in Figure A show a significant decrease in the distance crossed by non-diabetic lots treated with quercetin (NDQ) and diabetic ones treated with cinnamon and quercitrin (DCQ). Similarly to the non-diabetic batch treated with cinnamon and quercetin, it shows a very significant decrease between the $7^{\text {th }}$ and $14^{\text {th }}$ day.

\section{A}

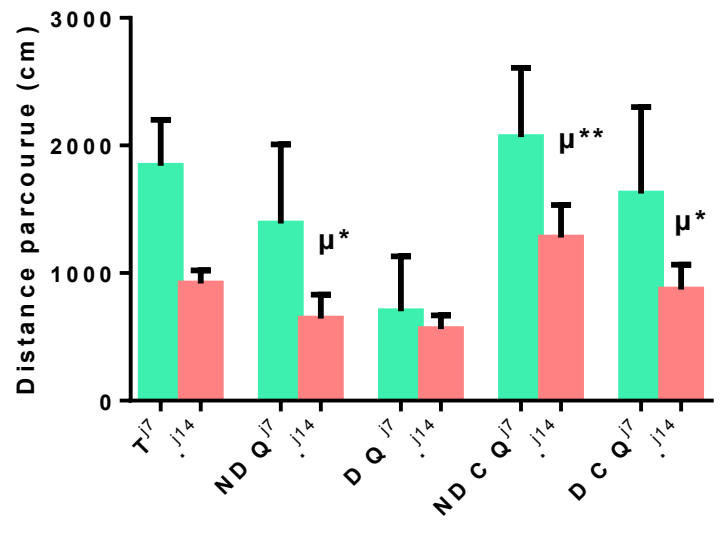

Regarding the $2^{\text {nd }}$ parameter, which is the number of rectifications expressed in Figure $\mathrm{B}$, a significant decrease $(P$ $<0.05)$ is noticed on the $14^{\text {th }}$ day of the diabetic batch treated with quercetin (DQ) compared to the $7^{\text {th }}$ day.

The figure shows a very significant decrease $(P<0.01)$ for the non-diabetic lot treated with cinnamon and quercetin $($ NDCQ) and a highly significant decrease $(P<0.001)$ for the diabetic lot treated with cinnamon and quercetin (DCQ) at the $14^{\text {th }}$ day compared with the $7^{\text {th }}$ day.

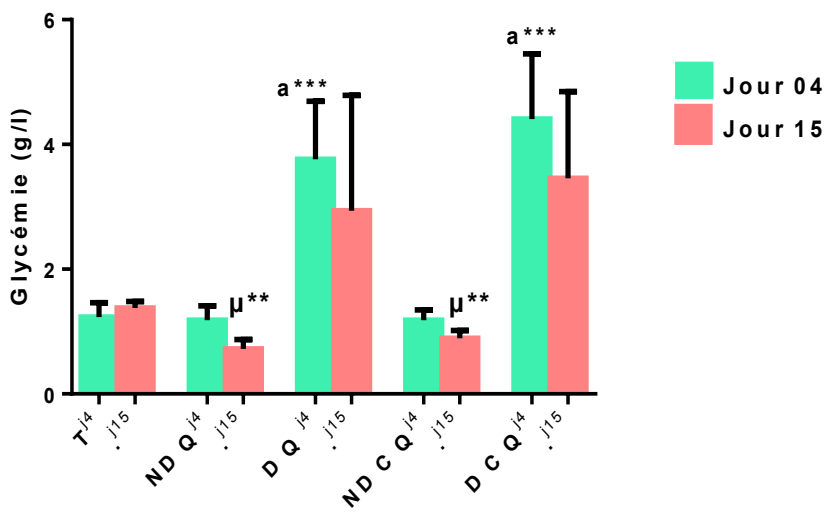

Figure 1 Changes in Glycemic Levels at Day 04 and 15 in the control group (T), Non-diabetic Treated with Quercetin (ND Q), Diabetic Treated with Quercetin (DQ) Rats, Non-Diabetic Rats treated with Cinnamon and Quercetin (ND CQ), diabetic rats treated with cinnamon and quercetin (DQC). a: Comparison between the control group and one of the batches; b: Comparison between non-diabetic treated lot and diabetic treated lot; $\mu$ : Comparison between days before and after treatment; Ns (Not significant difference) $(P>0.05$; * $P<0.05$; ** $P<0.01 ; * * * P<0.001)$

Figure 2 Variation of open field parameters in control (T), non-diabetic quercetin-treated (NDQ), diabetic quercetin-treated (DQ), non-diabetic cinnamon-treated and non-diabetic quercetin-treated (NDC Q), and diabetic rats treated with cinnamon and quercetin (DCQ). A; distance crossed by B; number of adjustments. Ns (Not significant difference) $(P>0.05 ; * P<0.05 ; * * P<0.01$; *** $P<0.001)$ 


\section{Triglycerides}

Triglyceride (expressed in $\mathrm{g} / \mathrm{l}$ ) was measured on the $15^{\text {th }}$ day. The figure shows that a lot of diabetic rats treated with quercetin $(\mathrm{DQ})$ indicated a significant increase $(P<0.05)$ compared with the batch of control rats $(\mathrm{T})$ and a significant increase $(P<0.05)$ in the batch of diabetic rats treated with quercetin (DQ) compared to the non-diabetic lot treated with quercetin.

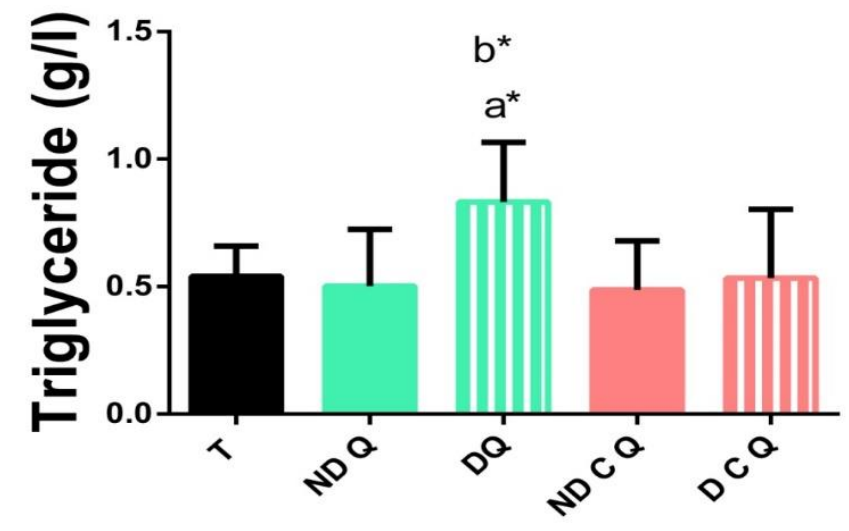

Figure 3 Variation of triglyceride in control $(\mathrm{T})$ rats, non-diabetic quercetin-treated (NDQ), diabetic quercetin-treated (DQ), nondiabetic, cinnamon and quercetin-treated (NDC Q) diabetic rats treated with cinnamon and quercetin (DCQ). The results are expressed as mean $\pm \operatorname{SEM}(\mathrm{n}=6)$. Ns (Not significant difference) $(P$ $>0.05$; $P<0.05$; ** $P<0.01$; *** $P<0.001)$

\section{Discussion}

Diabetes and depression are frequent pathologies whose impact on the lives of individuals is important. The number of people with diabetes has been estimated at 2.9 million. People with diabetes are much more exposed to mental suffering, especially depression (Thiebaut 2010).

Diabetes is defined as chronic hyperglycemia, which is a fasting blood glucose level above $1.26 \mathrm{~g} / 1$ ( $7 \mathrm{mmol} / \mathrm{l})$ twice (Grimaldi 2000). The use of medicinal plants plays an important role in the treatment of diabetes mellitus, many populations believe enormously in the effectiveness of these plants. Ethno-pharmacological and experimental studies have confirmed this property relating to plants to be able to control the glycemia of diabetics (Marleset Norman, 1994). The search for natural active ingredients from medicinal plants that can treat the metabolic disorders of diabetes is of great interest to health. Many herbs are traditionally considered as antidiabetic drugs, some of which are at the origin of the development of drugs such as metformin thanks to Galegaofficinalis (Witters 2001). Our results showed that the STZ injection (45 mg/kg) causes highly significant hyperglycemia $(P<0.001)$ after 72 hours of injection in diabetic rats treated with quercetin and in diabetic rats treated with cinnamon and quercetin which corresponds with the results of Daisy et al (2012), explaining this mechanism by direct toxicity on cells resulting in necrosis after 48 to 72 hours and causing permanent hyperglycemia.

The obtained results show a very significant decrease in the quercetin-treated rats which correspond with the results of Scalbert et al (2005) according to which, the polyphenols can have different actions on the peripheral tissues leading to a decrease in blood glucose, inhibition of gluconeogenesis and adrenergic stimulation of glucose uptake.

Cinnamon is known to have anti-diabetic properties; it is also perceived as an antioxidant with anti-inflammatory and anti-bacterial properties (Aggarwal and Sung 2009). In a metabolic syndrome model obtained using a high fructose diet, insulin resistance in animals is decreased by administration of $300 \mathrm{mg}$ of aqueous extracts of cinnamon/day (Qin et al 2004). On the genetic model of diabetic rats, the sensitivity to insulin is increased, and the hyperglycemia regulated by the administration of 50 to $200 \mathrm{mg}$ of aqueous extracts of cinnamon by the mechanism of action of the polyphenols of cinnamon on the cascade of Insulin signaling according to (Cao et al 2007).

Khan et al (1990) reported that the water-soluble compound of cinnamon potentiates insulin activity, and can improve the characteristic signs and symptoms of diabetes and cardiovascular diseases associated with insulin resistance. The insulin-like effect of cinnamon was initially attributed to its high chromium content, but no correlation could be established between chromium levels in cinnamon and its insulin-like activity. After this demonstration, 49 extracts of herbs, spices, and medicinal plants were evaluated to see how far they were insulin-like. Amongst the most effective compounds are cinnamon and green tea. (Broadhurst et al 2000).

Cinnamon is very rich in the cinnamic aldehyde. This volatile phenolic compound with antioxidant power has a quantity of dry matter that may exceed $17000 \mathrm{mg}$ per $100 \mathrm{~g}$ (Shan et al., 2005). An in vitro study on human blood samples has shown that cinnamic aldehyde can decrease the activity of an enzyme associated with the onset of inflammatory or allergic reactions (such as asthma, allergic rhinitis, and psoriasis) (Prasad et al 2004).

This extract can also reduce blood glucose and lipid levels in chemically diabetic rats. It increases the level of circulating insulin and restores the activity of plasma enzymes (Subash 2007). Cinnamic acid and its derivatives have a variety of pharmacological properties including antioxidant and hypoglycemic activity (Duke 1992).

2-Alkoxydihydrocinnamate functions as a peroxisome proliferator-activated receptor (PPAR) agonist. In genetically diabetic (ZDF) rats, this compound leads to a reduction in blood glucose and triglyceride levels (Martin et al 2006). 
The naphthalenemethyl ester; a derivative of dihydroxyhydrocinnamic acid, normalizes blood glucose in chemically or genetically diabetic rats and dramatically increases glucose transport by activating translocation of GLUT-4 (Kim et al 2006).

P-methoxycinnamic acid causes a decrease in the concentration of blood glucose and normalizes the activity of glucose-6-phosphatase, hexokinase, glucokinase, phosphofructokinase, glycogen, and glucose- 6-phosphate (Adisakwattana et al., 2005).

Recently, the polyphenolic polymers responsible for the potentiating effect of insulin have been identified in aqueous extracts of various kinds of commercially available cinnamon (Anderson et al 2004).

Stress is among the most important factors that negatively affect neurogenesis based on a recently developed concept that polyphenols are positive modulators of neurogenesis and stress resistance factors. Several studies in both animals and humans have reported the benefits of flavonoid intake and supplementation or on mental health. The administration of quercetin to animals undergoing acute stress suppresses activation of the hypothalamic-pituitary-adrenal (HPA) axis, which is a major component of the stress response and plays a major role in the etiology of stress-related pathologies (Roussel et al 2013).

Lots of researches have shown the hypoglycaemic effect of several plants containing polysaccharides, terpenes, flavonoids, and several other compounds (Sarkhail et al 2007). Developed by Hall and Ballechey, the open field is used to assess the anxiety-type emotional state and the level of locomotor and exploratory activity of the animal. The experiment is based on the natural aversive behavior of the animal concerning the discovered environments.

This test evaluates the reaction of an animal to a new and spacious environment. It creates a conflict situation between the animal's natural tendency to explore this new environment and its aversion to open spaces.

As a result, normal animals tend to spend more time in the corners and periphery of the device than in the center, which is then considered the most anxiety-provoking area (Crawley 1999; Prut and Belzung 2003; Elizalde et al 2008).

Our results highlight the significant decrease in distance crossed as well as the number of recoveries by quercetin-treated diabetic rats and diabetic rats treated with cinnamon and quercetin whose anxiety is the main cause. In agreement with the work done by Schmitt and Hiemke (1998) and Prut and Belzung (2003) who reported that the reduction in distance crossed in the device by stressed rats indicates a decrease in exploratory activity characteristic of a higher level of anxiety in rats.

Because of these observations, the relationship between diabetes and triglycerides is born from hormone insulin. Secreted by the pancreas, it regulates glucose levels in the blood (blood glucose). In diabetics, insulin production is low or zero. The glucose level goes up; it's the hyperglycemia. Since triglycerides result from the breakdown of glucose, their level is also higher in diabetes: it is called hypertriglyceridemia.

\section{Conclusions}

The conducted study consisted of mounting experimental diabetes in adult female rats of the Wistar strain, caused by a single intraperitoneal injection containing streptozotocin at $45 \mathrm{mg} / \mathrm{kg}$, which induced type 1 diabetes accompanied by neurobehavioral disturbances and also a decrease in weight as well as changes in lipid parameters. As a therapy, we opted for a treatment based on natural antioxidants of cinnamon and quercetin to see their remedial effects on the various complications related to experimental diabetes. The results show that these molecules stimulate the restorative responses of the body by limiting the damage caused by diabetes, prevent hyperglycemia, and restore weight loss. Herbal medicine offers solutions to heal with plants; it is a solution both alternative and complementary to conventional medical treatments, increasingly popular, and whose effectiveness is increasingly recognized.

\section{Conflict of Interest}

The authors declare no conflict of interest.

\section{References}

Adisakwattana S, Roengsamran S, Hsu WH, Yibchok-anun S (2005) Mechanisms of antihyperglycemic effect of p-methoxycinnamic acid in normal and streptozotocin-induced diabetic rats. Life Sci 78:406412.

Aggarwal BB, Sung B (2009) Pharmacological basis for the role of curcumin in chronic diseases: an age-old spice with modern tragets trend pharmacol. Science 30:85-94

Anderson P, Phillips K, Stoecklin G, Kedersha N (2004) Posttranscriptional regulation of proinflammatory proteins. Journal of Leukocyte Biology 76:42-47.

Broadhurst CL, Polansky MM, Anderson RA (2000) Insulin-like biological activity of culinary and medicinal plant aqueous extracts in vitro. Journal of Agricultural and Food Chemistry 48:849-852.

Bruneton R.L.Antimicrobial (1999) antioxidant and cytotoxic activities and phytochemical screening o some yemeni medicinal plants. Evidence Complementary and Alternative Medecine 7:323330 .

Cao H, Polansky M, Anderson RA (2007) Cinnamon extract and polyphenols affect the expression of tristetraprolin, insulin receptor, and glucose transporter 4 in mouse 3T3-L1 adipocytes. Archives of Biochemistry and Biophysics 459:214-222.

Crawley JN (1999) Behavioral phenotyping of transgenic and knockout mice: experimental design and evaluation of general health, sensory functions, motor abilities, and specific behavioral tests. Brain Research 835:18-26. 
David J, Alvin CP (2013) La polyneuropathie diabétique douloureuse. Médecine clinique endocrinologie et diabète 56:21-28.

Daisy P, Feril G, Kani J (2012) Evaluation of antidiabetic activity of various extracts of cassia auriculata linn. Bark on streptozotocin induced diabetic wistar rats. International Journal of Pharmacy and Pharmaceutical Sciences 4:312-318.

Delpech R (2015) état des lieux passé et actuel de l'insuline (thérapies et procédés) et perspectives d'évolution. Thèse de doctorat, pharmacie, université Toulouse paul sabatier, France.

Duke J (1992) Handbook of Phytomedical Constituents of GRAS Herbs and Other Economic Plants. Boca Raton, FL Press, Inc.

Elizalde N, Gil-Bea FJ, Ramirez MJ, Aisa B, Lasheras B, Del Rio J, Tordea RM (2008) Long-lasting behavioral effects and recognition memory deficit induced by chronic mild stress in mice: effect of antidepressant treatment. Psychopharmacology199:1-14.

Etuk E, Muhammed B (2010) Evidence Based Analysis of Chemical Method of Induction of Diabetes Mellitus in Experimental Animals. International Journal of Research in Pharmaceutical Sciences 1:2.

Ghika (2003) Intervention and cardiovascular disease in patients with type 2 diabetes 348:383-93.

Grimaldi A (2000) Diabétologie, Questions d'internat, université Pierre et Marie Curie, Faculté de médecine pp15 ,19, 29:142.

Hall CS (1934) Emotional behavior in the rat. Journal of Comparative Physical 18:385-403

Hernández I, Alegre L, Van Breusegem F, Munné-Bosch S (2009) Trends in Plant Science 14:125-132.

Hiramatsu Y, Sekiguchi N, Hayashi M, Isshiki K, Yokota T, King GL, Loeken MR (2002) Diacylglycerol production and protein Kinase $\mathrm{C}$ activity are increased in a mouse model of diabetic embryopathy diabetes 51:2804-2810.

Karl T, Pabst R, Von Horsten S (2003) Behavioral phenotyping of mice in pharmacological and toxicological research. Experimental Toxicology Pathology 55:69-83

Khan A, Bryden NA, Polansky MM, Anderson RA (1990) Insulin potentiating factor and chromium content of selected foods and spices. Biological Trace Elements Research 24:183-188.

Kim W, Khil L Y, Clark R, Bok S. H, Kim E. E, Lee S, Jun H. S , Yoon J. W (2006) Naphthalenemethyl ester derivative of dihydroxyhydrocinnamic acid, a component of cinnamon, increases glucose disposal by enhancing translocation of glucose transporter 4 . Diabetologia 49: 2437-2448.

Marles R.J, Norman R.F (1994) Plants as source of antidiabetic agents. In, Economic and medicinal plants research, London, H, Wagner and N.R., Farwoth, 112-09

Martin J, Wang ZQ, Zhang XH, Wachtel D, Volaufova J, Matthews DE, Cefalu WT (2006) Chromium picolinate supplementation attenuates body weight gain and increases insulin sensitivity in subjects with type 2 diabetes. Diabetes Care 29:1826-1832.
Prasad NS, Raghavendra R, Lokesh BR, Naidu KA (2004) Spice phenolics inhibit human PMNL 5-lipoxygenase. Prostaglandins Leukot Essent Fatty Acids 70:521-528.

Prut L, Belzung C (2003) The open field as a paradigm to measure the effects of drugs on anxiety-like behaviors: a review. European Journal of Pharmacology 463:3

Qin B, Nagasaki M, Ren M, Bajotto G, Oshida Y, Sato Y (2004) Cinnamon extract prevents the insulin resistance induced by a highfructose diet. Horm Metab Res 36:119-125.

Roussel.A.M (2013) Prise en charge du stress et de l'anxiété: Quelle place pour les composés bio-actifs naturels? la lettre de l'Institut Européen de Physionutrition et de Phytothérapie 28:4-6.

Saffidine K (2015) Etude analytique et biologique des flavonoïdes extraits de Carthamus caeruleus L. et de Plantago major L, thèse de doctorat, microbiologie,université Farhat Abes Sétif, Algérie, pp 4,15

Sanez A, Villagro OR (2006) Trias JF.Factor analysis of forced swimming test, Sucrose Perferance test and Open Field test on enriched, social and isolated reared rats. Behavior Brain Research 169:57-65.

Sarakhail P, Rahmanipour S, Fadyevatan S, Mohammadirad A, Dehghan G, Amin G, Shafiee A, Abdollahi M (2007) Antidiabetic effect of Phlomis anisodonta: Effects on hepatic cells lipid peroxidation and antioxidant enzymes in experimental diabetes. Pharmacological Research 56:261-266.

Scalbert A, Manach C, Morand C, Remesy C, Jimenez, L (2005) Dietary polyphenols and the prevention of diseases. Critical Reviews in Food Science and Nutrition 45:287-306.

Shan B, Cai Y.Z, Sun M, Corke, H (2005) Antioxidant capacity of 26 spice extracts and characterization of their phenolic constituents. Journal of Agricultural and Food Chemistry 53:7749-7759.

Subash BP, Prabuseenivasan S, Ignacimuthu S (2007) Cinnamaldehyde - a potential antidiabetic agent. Phytomedicine $14: 15-22$.

Surwit L (2002) Neuropathic pain. Redefinition and a grading system for clinical and research purposes. Neurology 70:1630-1635

Thiebaut S, Guillaume S, Courtet P (2010) dépression et diabète. CHU Montpellier \& Université de Montpellier, France, pp 02-04.

Urquiaga I, Leighton F (2000) Plant polyphenol antioxidant and oxidative stress. Biological Research 33:55-6411.

Wens J, Sunaert P, Nobels F, Feyen L, Crombruggen P.C, Bastiaens H, Royen PV (2007) Diabète Sucré de type 2 Société Scientifique de Médecine Générale SSMG; pp. 7-71.

Witters LA (2001) The blooming of the French lilac. The journal of clinical investigation 108:1105-1107. 